\title{
AS APOCYNACEAE DA REGIÃO DE POÇOS DE CALDAS, MINAS GERAIS, BRASIL
}

\author{
Marina Bragatto Vasconcellos ${ }^{1}$ \\ Luiza Sumiko Kinoshita Gouvea ${ }^{1}$
}

Recebido em 25-5-92. Aceito em 29-6-93

RESUMO - Este trabalho consiste no estudo florístico da familia Apocynaceae em Poços de Caldas, dada sua representatividade na regiảo e o valor fitoquímico e ornamental de várias de suas espécies. Foram encontradas 17 espécies distribuídas entre 8 gêneros: Aspidosperma Mart. e Zucc., Condylocarpon Desf., Forsteronia G.F.W. Mey., Macrosiphonia Muell. Arg., Mandevilla Lindl., Peltastes R.E. Woodson, Prestonia R. Br. e Rauvolfia L.

Palavras-chave: Estudo florístico, Apocynaceae, Poços de Caldas, Minas Gerais, Brasil.

\begin{abstract}
A floristic study of the family Apocynaceae im Poços de Caldas was carried out, since the family is well represented in the region and many species have phytochermical and ornamental value. The family is represented by 17 species distributed in 8 genera: Aspidosperma Mart. e Zucc., Condylocarpon Desf., Forsteronia G.F.W. Mey., Macrosiphonia Muell. Arg., Mandevilla Lindl., Peltastes R.E. Woodson, Prestonia R. Br. and Rauvolfia L.
\end{abstract}

Key words: Floristic study, Apocynaceae, Poços de Caldas, Minas Gerais, Brazil.

\section{Introdução}

Poços de Caldas, Minas Gerais, constitui um município tipicamente turístico, devido a suas peculiaridades de clima, águas termais e medicinais e vegetação nativa exuberante.

1 - Departamento de Botânica - IB - Cx. P. 6109, Universidade Estadual de Campinas, CEP 13081-970 - Campinas - SP 
A região Caldense também é rica em jazidas minerais e, por esta razão, constantes explorações têm causado o devastamento e a modificação de sua composição paisagística. Até o momento, muito pouco tem sido feito para a recuperação das áreas desnudiadas pela mineração. Em 1980 a Companhia Geral de Minas (atual ALCOA), que explora bauxita no município, preocupada com as consequências de sua mineração, propós um convênio ao Departamento de Botânica da Universidade Estadual de Campinas, com o propósito de estudar e promover a recuperação das áreas mineradas, pela recomposição da paisagem com espécies vegetais nativas. Deste estudo resultaram coleçōes botânicas significativas e, em termos florísticos, algumas familias bem representadas na região foram selecionadas para um estudo taxonômico.

0 presente trabalho representa uma contribuição ao conhecimento florístico de Poços de Caldas através do estudo da familia Apocynaceae, escolhida por estar bem representada na região e pelo valor ornamental e fitoquímico de várias de suas espécies.

\section{Materiais e Métodos}

Poços de Caldas está situada no sudoeste do Estado de Minas Gerais, a 21+51'20" latitude S e 46+33'55" longitude W (Candido \& Griffith, 1978), ocupando um planalto de cerca de $1500 \mathrm{~m}$ de altitude. Está circundada por serras que variam em altitudes de 1200 a $1500 \mathrm{~m}$, as quais fazem parte do sistema orográfico da serra da mantiqueira, tomando os seguintes nomes: Serra de Poços ao norte e oeste, Serra de Caldas a leste e Serra do Caracol ao sul (Mourão, 1951).

Para a execução deste trabalho, na maioria das vezes, foi examinado material herborizado, cujas exsicatas estão depositadas no Herbário da Universidade Estadual de Campinas (UEC), fazendo parte da coleção FPC. Para coleta deste material foram foram realizadas 21 viagens no periodo de 1980 a 1983 , e mais uma viagem em 1984, às áreas consideradas representativas dos principais ambientes que ocorrem no município (Figura 1). Também foram examinadas exsicatas provenientes de outras áreas da região, depositadas em herbários das seguintes instituiçōes: Instituto de Botânica de São Paulo (SP), Jardim Botânico do Rio de Janeiro (RB), Museu de História Natural da Universidade de Minas Ge-rais (BHMH), Museu Nacional (R) e "Swedish Museum of Natural History" (S).

As indentificaçöes foram baseadas em caracteres morfológicos, florais e vegetativos, aliados à literatura específica: Mueller(1860), Woodson (1930, 1933, 1935, 1936), Azambuja (1947), Markgraf (1968) e Fallen (1983).

0 habitat e a fenologia considerados para cada espécie foram os descritos pelos coletores, além dos mencionados na literatura. 


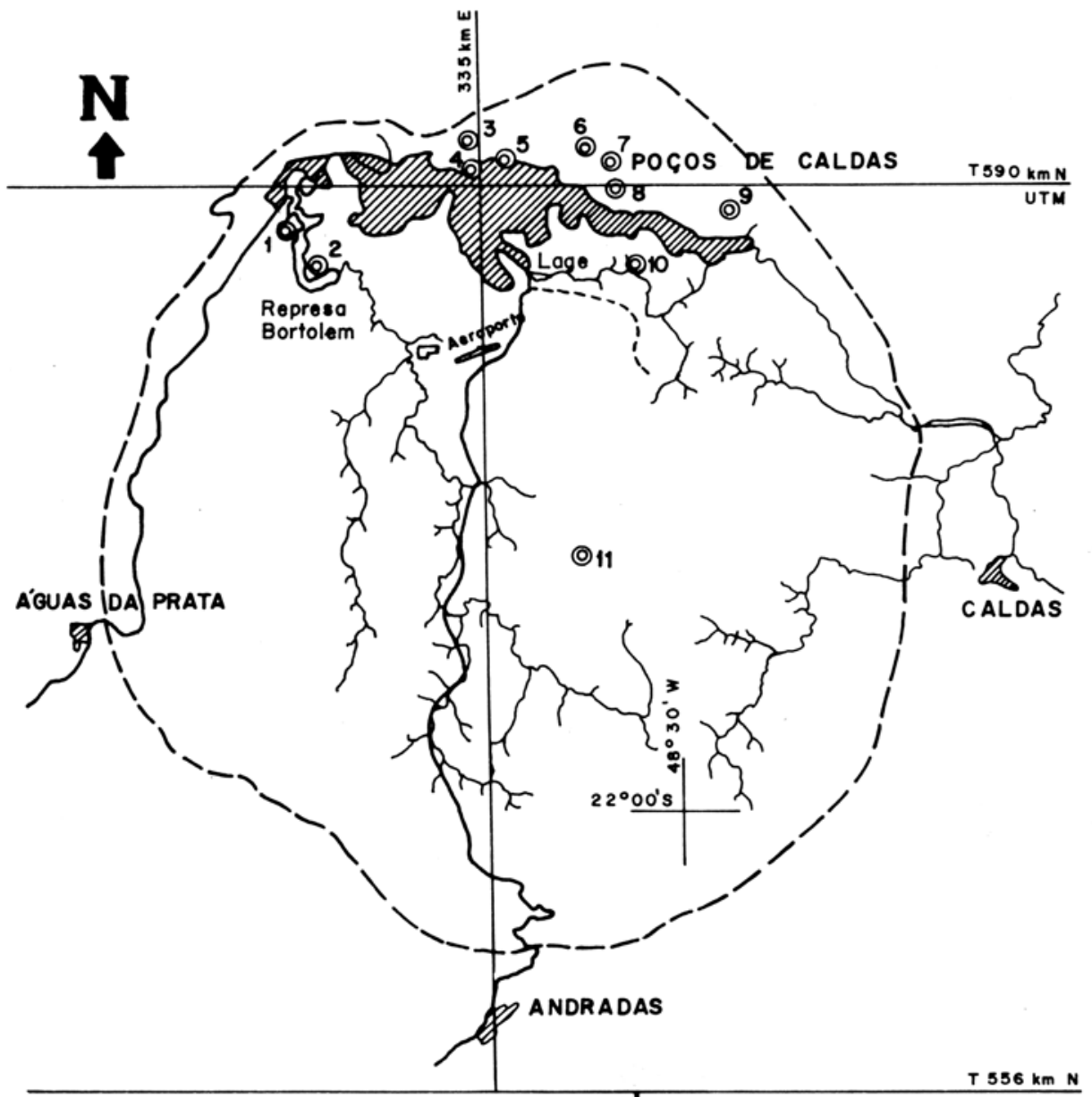

MAPA GERAL DO PLANALTO DE POÇOS DE CALDAS, MG

CONVENÇ OES

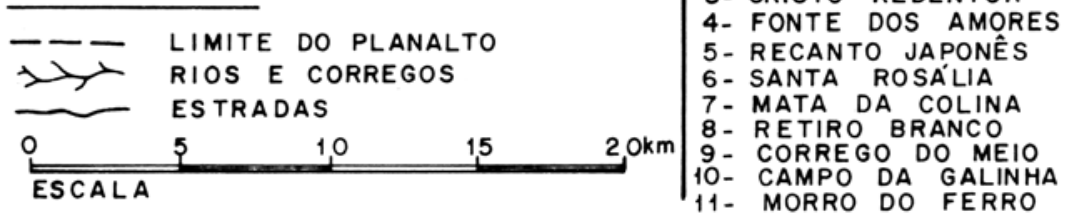

Figura 1 - Locais de coleta no município de Poços de Caldas. 


\section{Resultados e Conclusões}

Na região de Poços de Caldas foram encontradas 17 espécies da família Apocynaceae distribuídas entre 8 gêneros.

Chave para identificação dos gêneros:

1 - Lóculos da antera totalmente férteis

2 - Folhas alternas

1- Aspidosperma

2 - Folhas opostas ou verticiladas

3 - Disco presente. Árvore 2 - Rauvolfia

3 ' - Disco ausente. Trepadeira 3 - Condylocarpon 1' - Lóculos da antera parcialmente férteis.

4 - Folhas peltadas 4 - Peltastes

4' - Folhas não peltadas

5 - Tubo completo da corola com 0,1-0,3cm de comprimento, ápice das anteas excluso 5 - Forsteronia

5' - Tubo completo da corola com 1,3-14cm de comprimento, ápice das anteras incluso.

6 - Fauce com reforço em anel, tubo completo da corola com $1-1,5 \mathrm{~cm}$ de comprimento 6 - Prestonia

6 ' - Fauce sem reforço em anel, tubo completo da corola com $1,3-14 \mathrm{~cm}$ de comprimento.

7 - Corola creme-esbranquiçada, tubo completo da corola com $7-14 \mathrm{~cm}$ de comprimento 7' - Macrosiphonia

7 - Corola rósea, rósea-avermelhada ou amarela, tubo completo da corola com $1,3-5,5 \mathrm{~cm}$ de comprimento 8 - Mandevilla

1 - Aspidosperma australe Muell. Arg. in Mart., Fl. Bras. 6(1):58. 1860.

Árvore de até $8 \mathrm{~m}$ de altura. Folhas alternas, lanceoladas, longo-pecioladas, ápice subagudo a obtuso, base atenuado-cuneada, glabras, firmemente membranáceas, verde-escuras na face superior, verde-claras na face inferior, com 6,6-10cm de comprimento e 2-2,5cm de largura. Inflorescência em dicásio composto modificado, axilar, densa, próxima dos ápices dos ramos, adpresso-pilosa. Flores de coloração creme-esverdeada. Sépalas ovais, agudas, adpresso-pilosas. Corola tubulosa, seríceo-pilosa externamente, lobos ovais. Estames inseridos no terço superior do tubo, anteras sésseis. Gineceu apocárpico, ovário largamente oval, sedoso-piloso, estigma capitado-oblongo. Fruto não visto.

Fenologia: flores entre os meses de setembro a janeiro; frutos entre novembro e março.

Nome popular: peroba, guatambú, pequiá.

Habitat: ocorre em mata. 
Material examinado: Minas Gerais: Poços de Caldas, 3 set. 1980, H.F. Leitão $F^{2}$ et al. 17(UEC); Mata da Colina, 24 nov. 1982, F.R. Martins et al. 1692 (UEC); 30 nov. 1983, F.R. Martins 2119 (UEC); 30 nov. 1983, F.R. Martins 2116 (UEC); 30 out. 1981, J.Y. Tamashiro et al. 1654 (UEC); Rodovia Poços de Caldas-Campestre, 1.dez. 1982, H.F. Leitão $F^{Q}$ et al. 1787 (UEC).

\section{2 - Rauvolfia sellowii Muell. Arg. in Mart., Fl. Bras. 6(1):33. 1860.}

\section{Figura 2}

Árvore de até $15 \mathrm{~m}$ de altura. Folhas verticiliadas, 4 por nó, obovais ou elípticas, ápice acuminado, base cuneada mais ou menos aguda, membranáceas, glabras, com $12,5-21,5 \mathrm{~cm}$ de comprimento e $4-6 \mathrm{~cm}$ de largura. Inflorescência terminal em cimeira corimbosa, ampla, com muitas flores. Sépalas ovadolanceolados com ápice breve acuminado.

Corola tubulosa, lacínios lanceoladas de ápice arredondado e bordos revolutos. Fauce da corola vilosa. Anteras subsésseis inseridas na fauce da corola. Estilete longo, com cerca de $2 \mathrm{~mm}$ de comprimento, estigma obtuso, com colarinho basal. Gineceu aporcárpico, ovário esférico, circundado por 5 nectários. Frutículo drupáceo, elipsóide, com cerca de $1 \mathrm{~cm}$ de comprimento, endocarpo duro, rugoso.

Fenologia: flores em outubro; frutos entre novembro e janeiro. As folhas caem durante o inverno.

Nome popular: jasmim-grado.

Habitat: é freqüente em mata mas pode ocorre em capoeiras.

Material examinado: Minas Gerais: Poços de Caldas, Recanto Japonês, 12 jan. 1981, L.A.F. Mathes et al. 673(UEC).

3 - Condylocarpon isthmicum (Vell.) A. DC., Prod. 8:381. 1844.

\section{Figura 3}

Trepadeira latescente. Folhas opostas ou verticiladas, 3 por nó, elípticas, ápice agudo a acuminado, base cuneada a atenuada, membranáceas a subcoriáceas, tomentosas ou glabras na face ventral, com tufo de tricomas na axila da nervura principal, glabras ou esparsamente pubescentes na face dorsal, com $3,6-9 \mathrm{~cm}$ de comprimento e $3-4 \mathrm{~cm}$ de largura. Inflorescência terminal, tirso de múltiplas flores, brácteas triangulares de ápice agudo, pubescentes. Flores creme, cálice campanulado com lacínios obtusos, pubérulos. Corola infundibuliforme, lobos com apêndices loriformes na margem esquerda e com manchas marromavermelhadas na face abaxial, tubo da corola com anel de tricomas na região de inserção dos estames. Anteras lanceoladas, filetes breves, inseridos no terço inferior do tubo. Gineceu apocárpico, ovário cônico, estilete curto, estigma capitado, piloso.

Folículo moniliforme com $10-15 \mathrm{~cm}$ de comprimento e 3-5 articulado. 


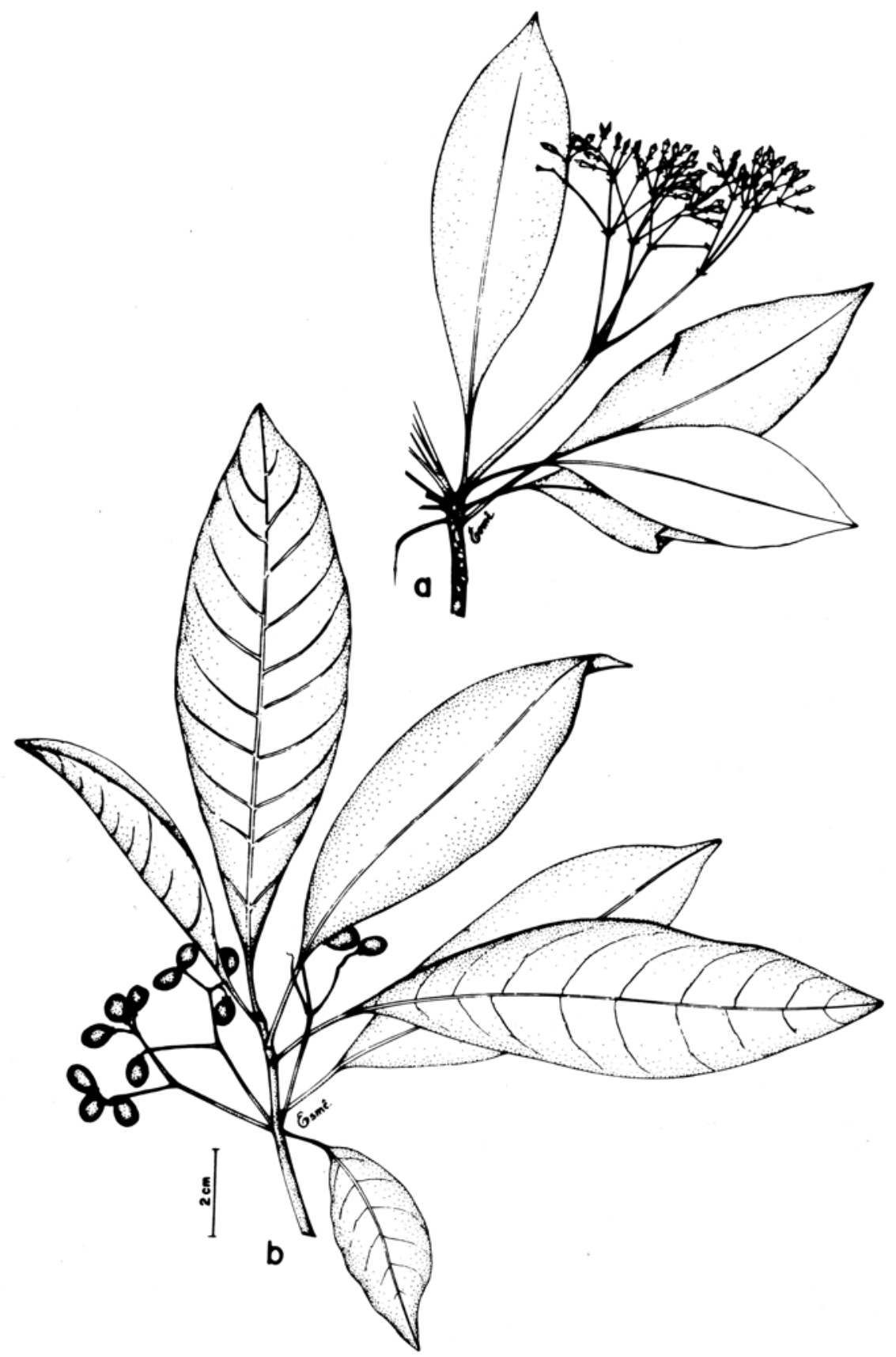

Figura 2 - Rauvolfia sellowii: a- ramo florífero, b- ramo frutífero. 
Fenologia: flores de outubro a dezembro; frutos de dezembro a maio.

Nome popular: cipó-leite, tênia.

Habitat: ocorre em mata.

Material examinado: Minas Gerais: Poços de Caldas, Mata da Colina, 14 out. 1981, J.Y. Tamashiro et al. 1217 (UEC); 16 out..1981, J.Y. Tamashiro et al. 1250 (UEC); Morro do ferro, 1 Dez. 1981, H.F. Leitão $F^{2}$ et al. 1463 (UEC); beira da

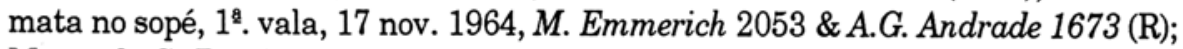
Morro de S. Domingos, 27 out. 1964, O. Leoncini \& O. Roppa 409 (R); Represa Saturnino de Brito, 19 out. 1964, O. Roppa 362(R).
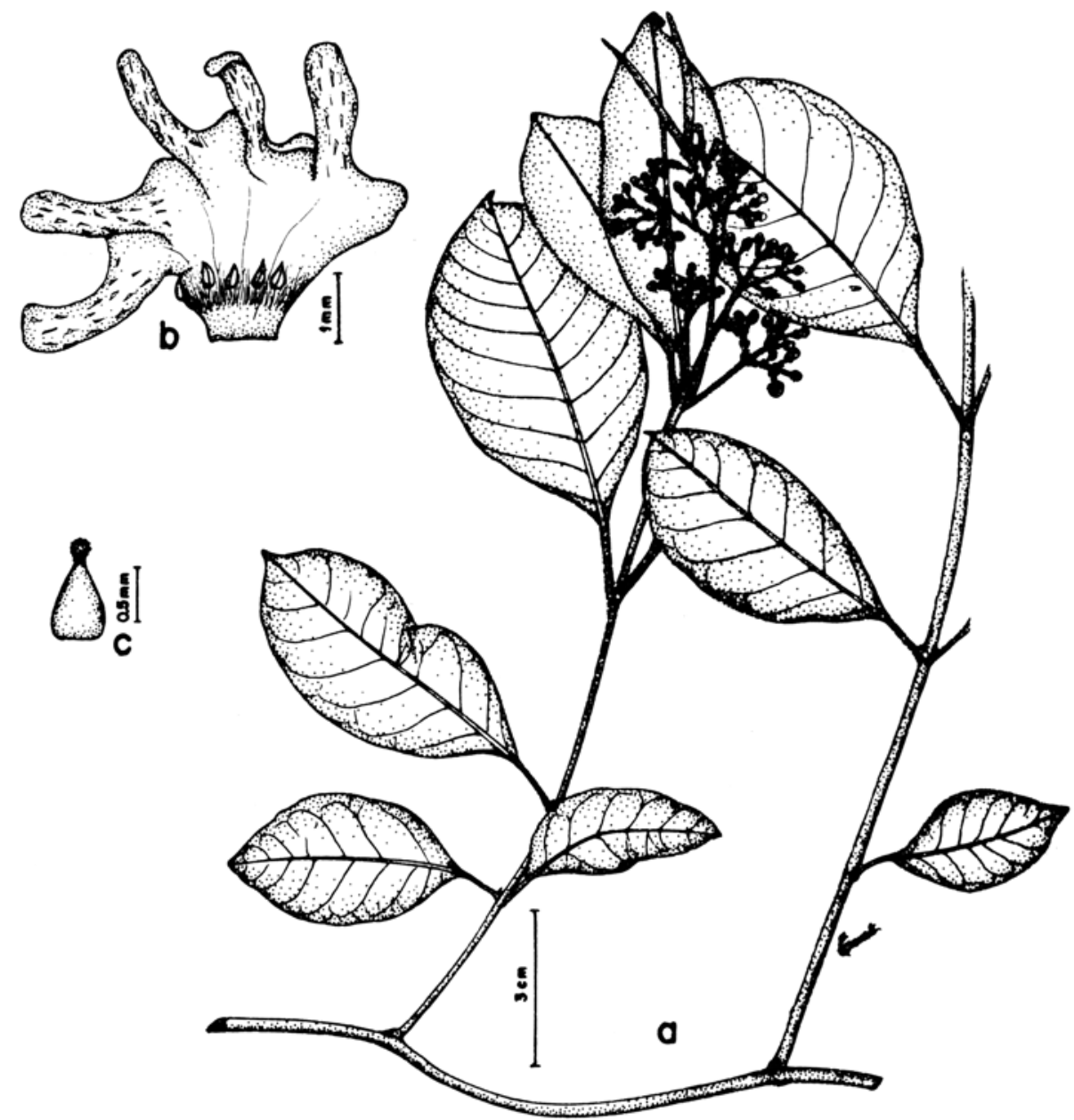

Figura 3 - Condylocarpon isthmicus: a- ramo florífero, b- corola aberta e estames, cgineceu. 
4 - Peltastes peltatus Woodson, Ann. Missouri Bot. Gard. 19:376. 1932.

Liana lenhosa, latescente, pubescente. Folhas opostas, peltadas, largamente ovais a elípticas, subcoriáceas, pilosas na face inferior, com 17-32 cm de comprimento e $9-17 \mathrm{~cm}$ de largura. Inflorescência lateral, cimosa, bracteada, densa, pilosa. Flores creme-esverdeadas. Sépalas oblongas, agudas, foliáceas, pouco pilosas, com muitas esquamelas uniformemente distribuídas. Corola com tubo inferior cilíndrico e tubo superior alargado em campainha, lobos obliquamente obovais. Anteras finamente hirsutas na face dorsal, sagitadas, longamente caudadas e aderidas ao estigma. Gineceu apocárpico, ovário circundado por 5 nectários, cabeça estigmática oblonga com colarinho basal estreito. Fruto não visto.

Fenologia: flores de outubro a fevereiro; frutos de dezembro a março.

Nome popular: cipó-benção.

Habitat: interior de mata, capão.

Material examinado: Minas Gerais: Poços de Caldas, Faz. Chiqueirão, 3 dez. 1981, H.F. Leitão $F^{Q}$. 1546(UEC); Morro do Ferro, 2 fev. 1982, H.F. Leitão $F^{Q}$. 1870(UEC).

5 - Macrosiphonia Muell. Arg. in Mart., Fl. Bras. 6(1):137. 1860.

Subarbusto ereto. Folhas opostas cruzadas, densamente lanuginosas. Inflorescência cimosa ou racemosa, terminal ou lateral, multiflora, pauciflora ou até reduzida a uma flor. Cálice profundamente partido, sépalas lineares, com esquamelas uniformemente distribuídas na base da face interna. Corola hipocrateriforme, com tubo inferior muito longo e estreito e tubo superior dilatado na altura da inserção dos estames, com lobos convolutos, dextrorsos. Estames inclusos, pilosos, adnados ao tubo da corola, anteras sagitadas coniventes e aderidas à cabeça estigmática, férteis somente na parte superior, biauriculadas, conectivo peltado, cabeça estigmática umbraculiforme. Ovário glabro, circundando por 5 nectários mais ou menos unidos. Fruto folicular, toruloso. Sementes elípticas com tufo apical de pelos.

Chave para as espécies:

1 - Folhas concolores, densamente albo-lanuginosas, de bordo liso, com 4-8cm de comprimento e $2-4 \mathrm{~cm}$ de largura 5.1 - M. velame

1' - Folhas discolores, com face superior esverdeada e com tricomas esparsos, face inferior esbranquiçada e densamente lanuginosa, bordo ligeiramente revoluto, com $3,5-4 \mathrm{~cm}$ de comprimento e $1,2-1,5 \mathrm{~cm}$ de largura 5.2 - M. longiflora 
5.1 - Macrosiphonia velame (St. Hil.) Muell. Arg. in Mart., Fl. Bras. 6(1):138. 1860.

Subarbusto densamente albo-lanuginoso. Folhas concolares densamente albolanuginosas em ambas as faces, oblongo-laneoladas, ápice acuminado e base obtusa, cartáceas, face inferior com nervuras proeminentes, com 4-8cm de comprimento e $2-4 \mathrm{~cm}$ de largura. Inflorencência racemosa, terminal, lanuginosa, com 2 6 flores, pedúnculo com $5 \mathrm{~cm}$ de comprimento. Cálice com sépalas linearlanceoladas, base alargada e ápice acuminado recurvado. Corola com tubo inferior de 8-10cm de comprimento e tubo superior de 1,5-2cm de comprimento, lacínios obovados, de bordos crispados. Antera com cerca de $1 \mathrm{~cm}$ de comprimento. Ovário com $3 \mathrm{~mm}$ de comprimento, circundando por nectários com cerca de $1 \mathrm{~mm}$ de comprimento. Folículo com $16 \mathrm{~cm}$ de comprimento, revestido por pilosidade branco-lanosa.

Fenologia: flores de outubro a abril, com predominância nos meses de novembro a fevereiro; frutos de janeiro a junho, com predominância em março e abril.

Nome popular: velame, velame-do-campo, velame-branco, losna-do-campo, jalapabranca, guaranitica.

Habitat: ocorre principalmente em cerrado aberto sujeito ao fogo, campo e ocasionalmente em floresta de galeria.

Material examinado: Minas Gerais: Poços de Caldas, Faz. Chiqueirão, 3 dez. 1981, H.F. Leitão $F^{2}$ et al. 1566 (UEC); Morro do Ferro, 8 mar. 1983, H.F. Leitão $F^{2} .2023$ (UEC).

5.2 -Macrosiphonia longiflora (Desf.) Muell. Arg. in Mart., Fl. Bras. 6(1):140. 1860.

\section{Figura 4}

Subarbusto com ramos albo-lanosos. Folhas discolores, face superior esverdeada, com tricomas longos e esparsos, face inferior esbranquiçada, densamente albo-lanuginosa, subsésseis, lanceolado-ovadas, ápice agudo, base levemente cordada, bordos ligeiramente revolutos, cartáceas, com 3-3,7cm de comprimento e 0,8-1,3cm de largura. Inflorescência racemosa lateral, com 1-4 flores, lanuginosa. Cálice com lobos lineares, glabros internamente, com 7-8 esquamelas. Corola com tubo inferior de 7,5-14cm de comprimento e tubo superior de $1,5-4 \mathrm{~cm}$ de comprimento, lacínios obovados, de bordos crispados. Anteras com $1-3 \mathrm{~cm}$ de comprimento. Ovário com $2 \mathrm{~mm}$ de comprimento circundado por nectários com $1 \mathrm{~mm}$ de comprimento. Fruto não visto.

Fenologia: floresce praticamente o ano todo, com predominância entre setembro e dezembro; frutos entre os meses de outubro a maio, com predominância em fevereiro.

Nome Popular: flor-de-babado, jalapa-branca, velame-grande, velame-do-campo, babado-de-Nossa-Senhora.

Habitat: ocorre em campo. 
116

Vasconcellos \& Gouvea
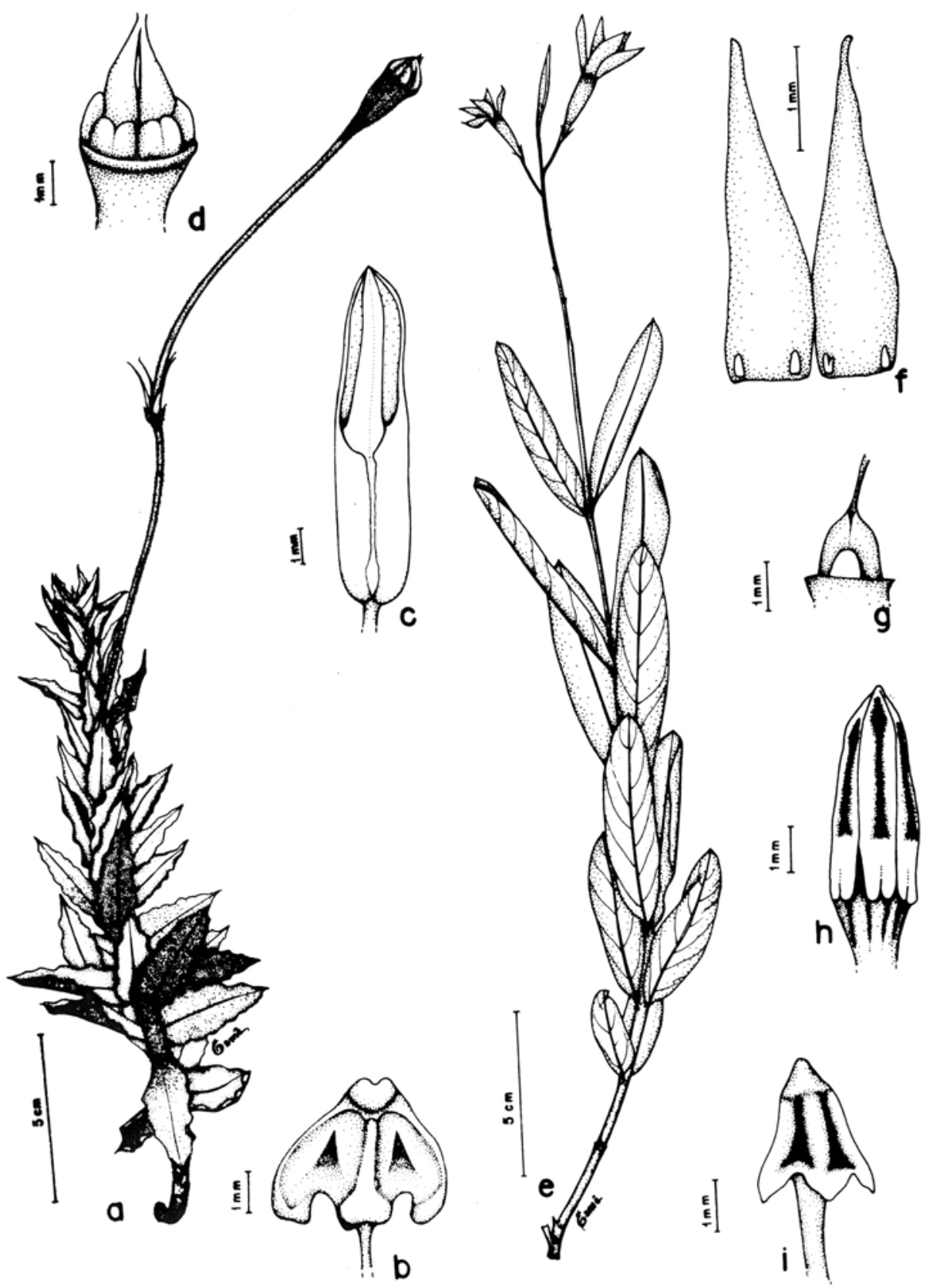

Figura 4 - a- Macrosiphonia longiflora - ramo florífero, b- estigma, c- antera, d- ovário com nectário, e- Mandevilla spigeliaefolia - ramo florífero, f- face interna de sépala com esquamelas, g- ovário com nectário, h- estames, i- estigma. 
Material examinado: Minas Gerais: Poços de Caldas, Contry Club, 3 nov. 1980, Mello Barreto 11096 (BHMH); Represa Saturnino de Brito, 19 out. 1964 (fl.), O. Leoncini \& O. Roppa 366 (R); Seminário, 25 out. 1964, O. Leoncini \& O. Roppa 405 (R), 16 set. 1966, O. Roppa 830 (R).

6 - Prestonia coalita (vell.) Woodson, Ann. Missouri Bot. Gard. 18:552. 1931.

Trepadeira latescente, delgada. Folhas opostas, oblongas ou elípticas, ápice agudo, base arredondada, membranáceas, glabras na face superior e pubérulas na face infeiror, com $7-14,5 \mathrm{~cm}$ de comprimento e $3,5-4,5 \mathrm{~cm}$ de largura. Inflorescência axilar, monocásio, bracteadas. Flores verde-amareladas, com cerca de $1-1,5 \mathrm{~cm}$ de comprimento. Cálice com sépalas lanceoladas. Corola com tubo cilíndrico de cerca de $1-1,5 \mathrm{~cm}$ de comprimento, lobos estendidos, um pouco reflexos. Estames inseridos no meio do tubo, anteras sagitadas ligadas firmemente à cabeça estigmática. Gineceu apocárpico, ovário com muitos óvulos, disco com 5 nectários. Fruto não visto.

Fenologia: flores de outubro a abril; frutos em junho.

Nome popular: cipó-de-paina, cipó-de-leite, cipó-capador.

Habitat: espécie heliófita e xerófita, encontrada principalmente em beira e clareira de mata, mas também em capoeira.

Material examinado: Minas Gerais: Poços de Caldas, 3 dez. 1982, H.F. Leitão $F^{q}$. 1919 (UEC); Faz. Chiqueirão, 3 dez. 1981, H.F. Leitão $F^{\circ}$ et al. 1591 (UEC); Rodovia Poços de Caldas-Campestre, 1 dez. 1982, H.F.Leitão F. 1820 (UEC).

7 - Forsteronia G. F. W. Mey, Prin. Fl. Essequeb. 133. 1818.

Trepadeira lenhosa, latescente. Folhas opostas. Inflorescência terminal multiflora, racemosa a cimosa, com brácteas. Flores pequenas, corola dextrorsa, tubo curto, não excedendo a $3 \mathrm{~mm}$ de comprimento, fauce sem reforço, lobos estendidos. Estames com anteras parcialmente férteis, de ápice excluso, sagitadas e firmemente aderidas ao estigmas. Gineceu apocárpico, ovário circundade por 5 nectários. Fruto folicular, alongado. Sementes truncadas, com tufo apical de pelos.

Chave para as espécies:

1 - Folha com limbo de 9-13cm de comprimento; inflorencência laxa, tirsiforme; filetes com 2 apêndices alados 7.1 - F. refracta

1' - Folha com limbo de até $4,3 \mathrm{~cm}$ de comprimento; inflorescência congesta, subcorimbosa; filetes sem apêndices alados 7.2 - F. velloziana 
7.1 - Forteronia refracta Muell. Arg. in Mart., Fl. Bras. 6,1:97. 1860.

Trepadeira com ramos glabros. Folhas pecioladas, oblanceoladas, elípticooblanceoladas, de ápice agudo a acuminado e base brevemente atenuada, membranácea a papirácea, glabras, face inferior com domácias nas axilas das nervuras principais, com $10-20 \mathrm{~cm}$ de comprimento e $3-5 \mathrm{~cm}$ de largura. Inflorescência terminal, laxa, tirsiforme, glabra, brácteas ovado-lanceoladas, ciliadas no ápice. Sépalas largamente ovais, ciliadas no ápice, com muitas esquamelas de distribuição irregular. Corola albo-esverdeada, pilosa internamente, lobos longamente ovais. Estames com filetes apresentando 2 pequenos apêndices alados, anteras sagitadas, firmemente aderidas ao estigma fusiforme. Ovário piloso alongado-ovóide. Fruto não visto.

Fenologia: flores em novembro e dezembro; frutos de março a junho.

Nome popular: cipó-de-leite.

Habitat: ocorre em mata.

Material examinado: Minas Gerais: Poços de Caldas, Mata da Colina, 15 out. 1980, F.R. Martins et al. 250 (UEC).

7.2 - Forteronia velloziana (A.DC.) Woodson, Ann. Missouri Bot. Gard. 21:622. 1934.

Figura 5

Trepadeira com ramos pubérculos. Folhas curto-pecioladas a subsésseis, oblongo-elípticas a largamente ovais, oblongo-elípticas a ovaladas, ápice curtamente acuminado, base subcordada, membranáceas, curtamente pilosas na face superior, curta e esparsamente hirtelas na face inferior, com glândulas inconspícuas na base na nervura central, com 2,5-4,5cm de comprimento e 1,5$1,8 \mathrm{~cm}$ de largura. Inflorencência terminal congesta, subcorimbosa, curtamente hirtela. Flores pequenas verde-amareladas, brácteas linear-lanceoladas, cálice com lobos lanceolados e esquamelas alternas, corola com tubo puberulento internamente. Estames inseridos na fauce da corola, glabros. Ovário ovóide, curtamente hirsuto. Fruto não visto.

Fenologia: flores em novembro.

Habitat: em campo e capão.

Material examinado: Minas Gerais: Poços de Caldas, Campos da Pedreira 6 nov. 1940, M. Barreto 10974 (BHMH); Campo de Santa Rosália, 17 nov. 1980. G. J. Shepherd 442 (UEC).

8 - Mandevilla Lindl., Bot. Reg. 26: tab. 7. 1840.

Arbusto, subarbusto, trepadeira lenhosa ou erva. Folhas opostas, opostas cruzadas ou raramente verticiladas, não peltadas, geralmente com pontuaçōes 
As Apocynaceae...

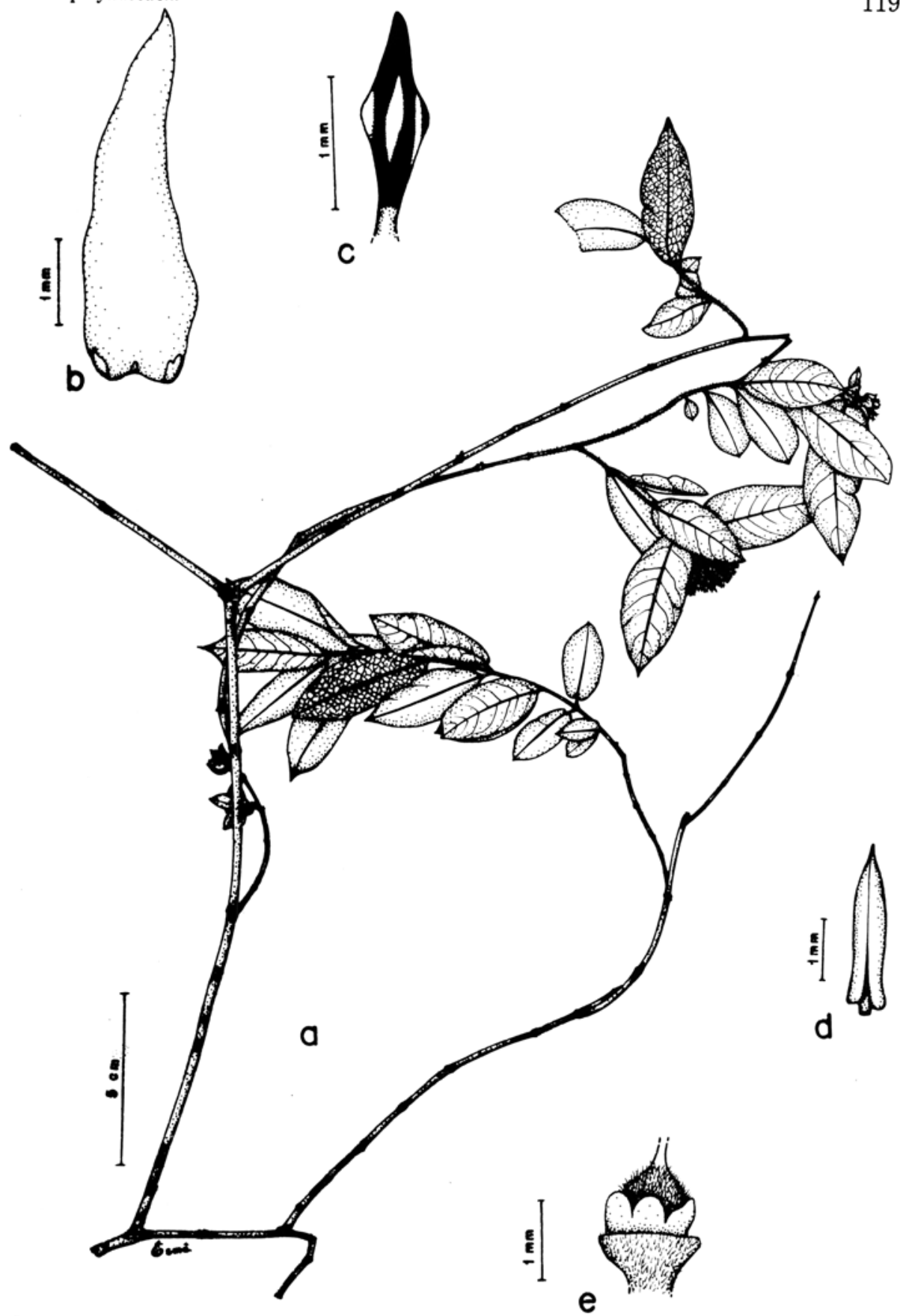

Figura 5 - Forsteronia velloziana: a- ramo florífero, b- face interna de sépala com esquamelas, c- estigma, d- antera, e- ovário com nectário. 
gladulares na base do limbo. Inflorencência monocasial, terminal ou axilar, com brácteas. Cálice com esquamelas na face interna das sépalas. Corola dextrorsa, fauce sem reforço, estames inclusos. Anteras parciamente férteis. Gineceu apocárpico, ovário circundado por 2 ou 5 nectários, cabeça estigmática umbraculiforme. Fruto folicular. Sementes elípticas, com tufo apical de pelos.

Chave para espécies:

1 - Corola infundibuliforme

2 - Trepadeira inteiramente pilosa, flores amarelas

$8.1-$ M. hirsuta

2 - Subarbusto ereto, piloso ou glabro, flores róseas.

3 - Planta cespitosa, com ramos jovens e folhas híspidas, tubo superior da corola estreito com fauce de $0,6-1,3 \mathrm{~cm}$ de diâmetro

8.2 - M. illustris

3' - Planta ramosa, inteiramente glabra, tubo superior da corola largo, com fauce de $1,4-2 \mathrm{~cm}$ de diâmetro

8.3 - M. venulosa

1' - Corola tubular a salverforme

4 - Inflorescência congesta no ápice, brácteas e cálice foliáceos, superando o tamanho da corola 8.4 - M. erecta

4' - Inflorencência laxa, cálice com lobos pequenos.

5 - Tubo superior da corola com $3-4 \mathrm{~cm}$ de comprimento

8.5 - M. velutina

5 ' - Tubo superior da corola com 0,3-1,7cm de comprimento.

6 - Folhas estreitamente lineares

$8.6-M$. tenuifolia

6 ' - Folhas elípticas, oblongo-elípticas, elíptico lanceoladas a oblongo-lanceoladas.

7 - Tubo superior da corola igual ou pouco maior que o tubo inferior, com $11,4 \mathrm{~cm}$ de comprimento

8.7 - M. coccinea

7 ' - Tubo superior da corola cerca de 3 vezes maior que o tubo inferior, com $1,3-1,7 \mathrm{~cm}$ de comprimento

8.8 - M. spigeliaefolia

8.1 - Mandevilla hirsuta (A. Rich.) K. Sch. in Engl. \& Prantl, Nat. Pflanzefam 4(2):171, 1895.

Trepadeira lenhosa, ramos cilíndricos, híspidos. Folhas opostas, oblongoelípticas, ápice abruptamente acuminado, base obscuramente auriculada, membranáceas a cartáceas, com 10,5-14,5cm de comprimento e 3-6,5cm de largura. Racemos laterais tão longos quanto as folhas, flores amarelo-avermelhadas, vistosas, brácteas petalóides, pilosas. Cálice com lobos ovado-lanceolados a lanceolados, híspidos, esquamelas opostas, solitárias, ligulares, subtriangulares, irregulargamente denteadas. Corola amarela, infundibuliforme, tomentosa, com 
tubo inferior ligeiramente giboso. Anteras auriculadas. Ovário ovóide, glabro, circundado por 5 nectários obovóide-compressos, pouco menores que o ovário, estigma curtamente apiculado. Folículo hirsuto, conspicuamente articulado ou moniliforme, com 13-14cm de comprimento.

Fenologia: Flores e frutos em dezembro.

Habitat: ocorre em mata.

Material examinado: Minas Gerais: Rodovia Poços de Caldas-Campestre, 1 dez. 1982 H.F. Leitão $F^{\circ}$. et al. 1781 (UEC).

\section{2 - Mandevilla illustris (Vell.) Woodson, Ann. Missouri Bot. Gard. 20:727.1933.}

Figura 6

Subarbusto ou erva ereta. Folhas opostas-cruzadas ou raramente verticiladas, subsésseis a curto-pecioladas, oblongo-elípticas, obovadas ou suborbiculares, ápice truncado a curtamente agudo até acuminado, base obtusa a arredondada, cartáceas, com $6-9 \mathrm{~cm}$ de comprimento e $3,5-7,7 \mathrm{~cm}$ de largura. Inflorencência terminal, racemosa, flores rosas ou coralinas, brácteas lanceoladas, acuminadas, pilosas nos bordos e ápice e cálice com lobos lanceolados a ovado-lanceolados, acuminados, esquamelas irregularmente denteadas alternas em grupos de dois. Corola infundibuliforme, rósea a róseo-avermelhada, com lobos ablíquamente obovados e curtamente acuminados. Estames com anteras auriculadas. Ovário ovóide, glabro, estigma curtamente apiculado, nectários 2, compresso-ovóides. Folículo com 10-37,5cm de comprimento, glabro.

Fenologia: flores de setembro a dezembro; frutos de outubro a janeiro.

Habitat: ocorre em campo.

Material examinado: Minas Gerais: Poços de Caldas, 30 nov. 1982, H.F. Leitão $F^{Q}$ 1718 (UEC); 2 out. 1980, HF. Leitão $F^{2} .61$ (UEC); 28 out. 1981, J. Y. Tamashiro et al. 1287 (UEC); 13 jan. 1981, L. S. K. Gouvêa et al. 747 (UEC); Caldas, 20 nov. 1873, Mosén 942 (S); 10 nov. 1875, Mosen 4261 (S); 20 nov. 1873, Mosén 943 (S); 18 dez. 1864, Regnell 280; Campo do Saco, 16 out. 1980, A.C. Gabrielli et al. 306 (UEC); 30 nov. 1981, H.F. Leitão $F^{2}$. 1368 B (UEC); 23 nov. 1964, M. Emmerich 2264 (R); 11 out. 1965, O Roppa 694 (R); Campo do Seminário, 20 set. 1965, O Roppa 687 (R); Cascata Véu das Noivas, 25 out. 1964, O. Roppa 108 (R); Contry Club, 2 nov. 1940, Melo Barreto 10925 (BHMH); km 69 da E.F. Mogiana, 10 nov. 1964, O. Leoncini 439 (R); Morro do Ferro, no vale a oeste do Morro, 16 out. 1964, O. Leoncini \& O. Roppa 335 (R); Serra de Caldas, 2 nov. 1861, Regnell I 280 (S).

Comentário: Pelo aspecto geral, M. illustris pode ser confundida com M. velutina, entretanto, são facilmente distintas pelo tubo superior da corola: $M$. illustris apresenta o tubo estreitamente cônico, com 1,5-2 cm de comprimento, enquanto M. velutina apresenta este tubo cilíndrico e com $3-4 \mathrm{~cm}$ de comprimento. 

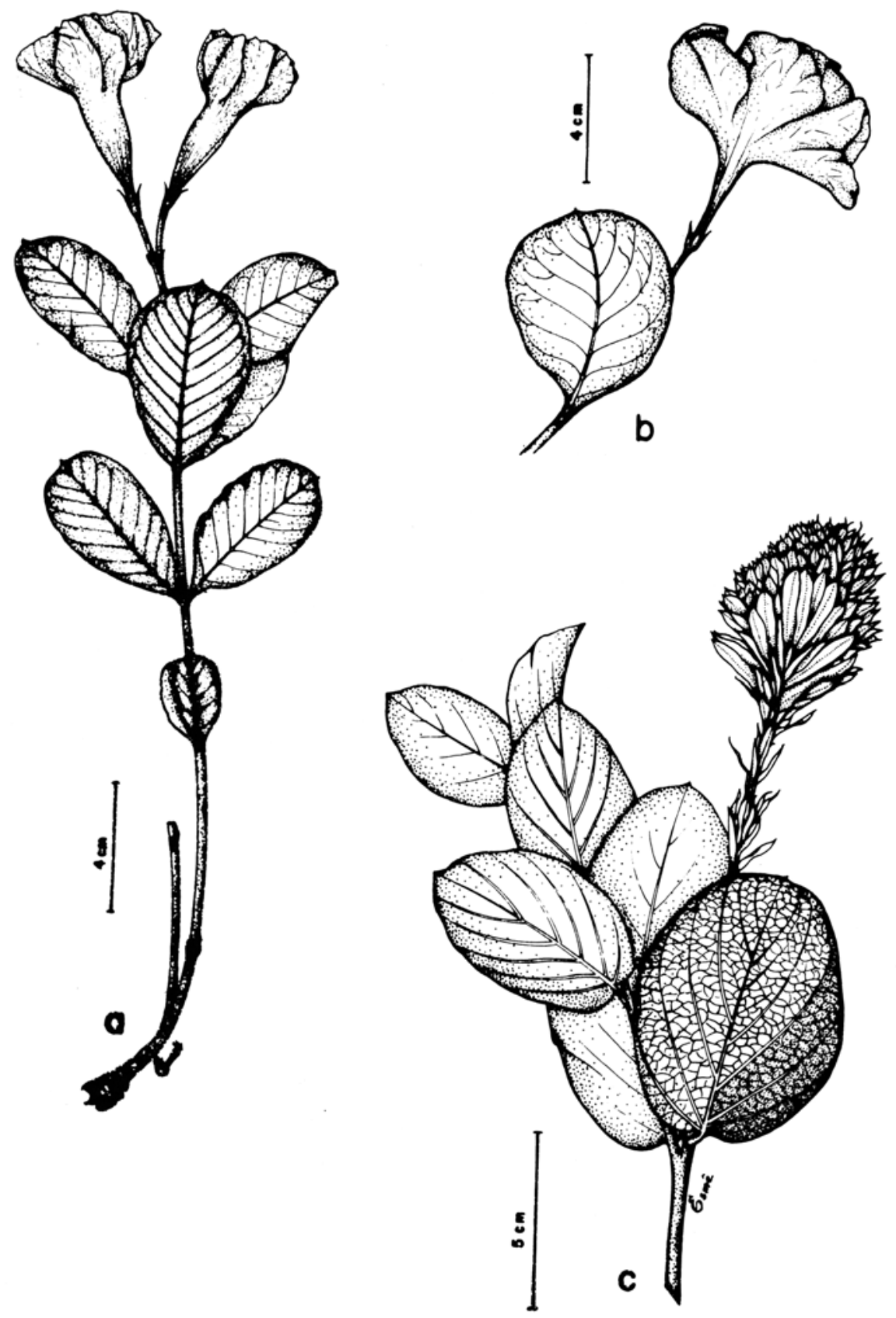

Figura 6 - a- Mandevilla velutina - ramo florífero, b- Mandevilla ilustris - ramo florífero, c- Mandevilla erecta: ramo florífero mostrando brácteas e sépalas foliáceas. 


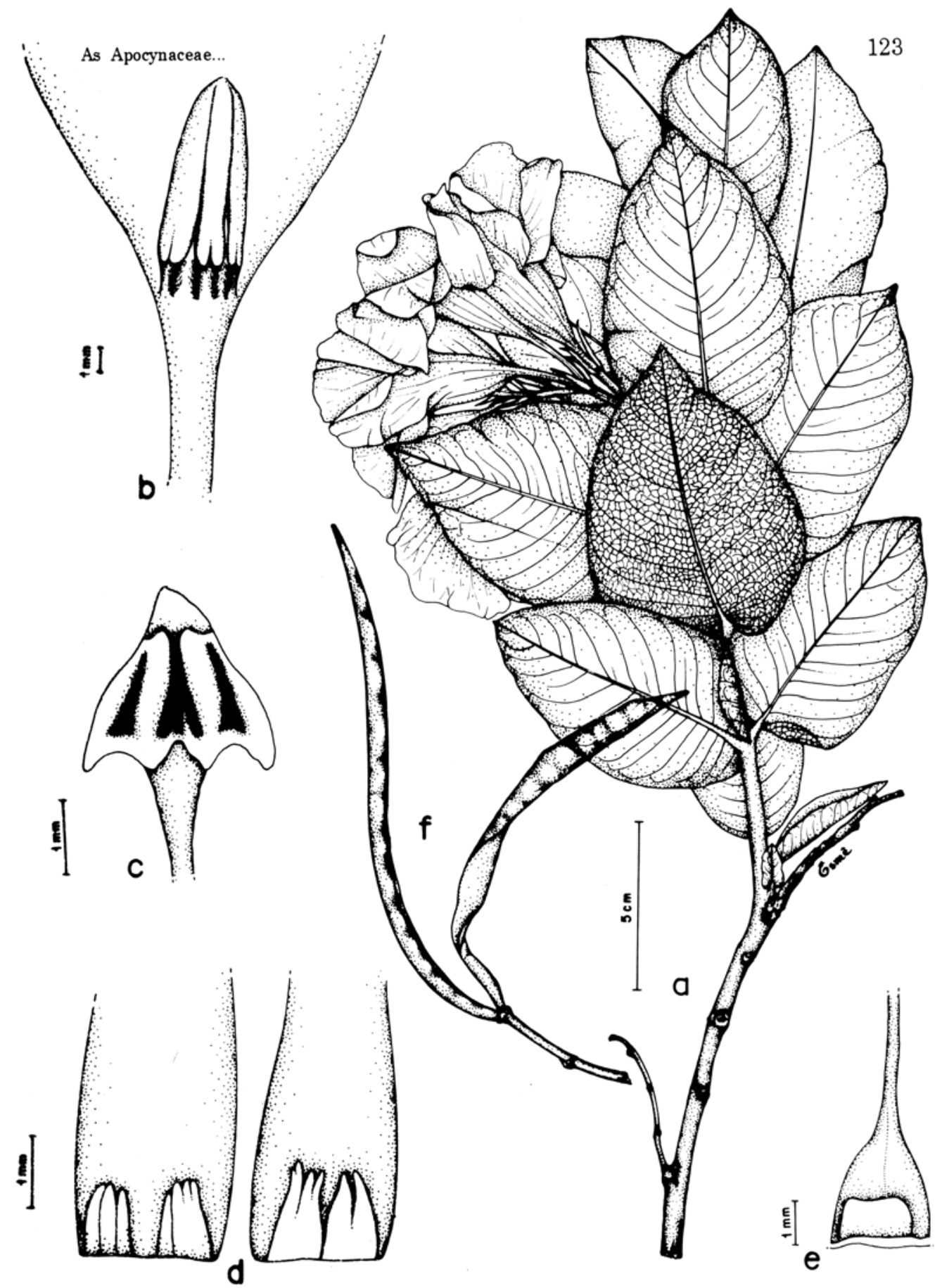

Figura 7: Mandevilla venulosa: a- ramo florífero, b- estames, c- estigma, d- face interna de sépalas com esquamelas, e- ovário com nectário, f- fruto. 
8.3 - Mandevilla venulosa (Muell. Arg.) Woodson, Ann. Missouri. Bot. Gard. 20:723. 1933

\section{Figura 7}

Subarbusto ereto ou subereto. Folhas opostas cruzadas, sésseis ou subsésseis, ovado-elípticas ou oblongo-elípticas de ápice obtuso ou ligeiramente acuminado e base cordada, subcoriáceas a coriáceas, com $6-12 \mathrm{~cm}$ de comprimento e $3,5-8,5 \mathrm{~cm}$ de largura. Racemos simples, subterminais. Flores grandes, vistosas, de cor creme a rosada. Cálice com lobos lanceolados, acuminados, escariosos, esquamelas em grupos irregulares ou indefinidamente distribuídas. Corola infundibuliforme, glabra, com lobos de ápice subtruncado. Estames com anteras auriculadas, esparsamente pilosas no dorso. Ovário oblongo, glabro, envolvido por 2 nectários reniformes. Estigma curtamente apiculado. Folículo com $13-18 \mathrm{~cm}$ de comprimento, glabro.

Fenologia: flores de setembro a março; frutos de outubro a abril.

Habitat: ocorre em campo.

Material examinado: Minas Gerais: Serra de Caldas, 20 out. 1875, Mosén 4265 (S); 10 dez. 1873, Mosén 947 (S); mar. 1847, Regnell 876 (S).

\section{4 - Mandevilla erecta (Vell.) Woodson, Ann. Missouri. Bot. Gard. 19:62.1932.}

\section{Figura 6}

Arbusto ereto. Folhas opostas, curtamente pecioladas a subsésseis, cordado ovais ou cordado-oblongas, ápice curto e abruptamente apiculado, base cordada, membranáceas a cartáceas, face inferior densamente tomentosa, face superior densa a esparsamente puberulenta, com $4,5-11 \mathrm{~cm}$ de comprimento e $2,5-8,5 \mathrm{~cm}$ de largura. Racemos simples, terminais ou subterminais, vistosas, com coloração amarelada. Brácteas e cálice foliáceos, estreitamente oblongo-lanceolados, superando o tamanho da corola. Corola tubular salverforme. Estames inseridos acima da metade do tubo da corola. Ovário oblongo-ovóide, glabro, nectários 5. Folículo com $17-20 \mathrm{~cm}$ de comprimento, glabro.

Fenologia: flores de setembro a fevereiro; frutos de outubro a março.

Nome popular: jalapa-do-campo.

Habitat: ocorre em campo.

Material examinado: Minas Gerais: Poços de Caldas, Campo do Saco, 30 out. 1981, J. Y. Tamashiro 1313 (UEC).

8.5 - Mandevilla velutina (Stadelm.) Woodson, Ann. Missouri, Bot. Gard. 20:731. 1933.

Subarbusto ou erva ereta. Folhas opostas-cruzadas, curtamente pecioladas a subsésseis, oblongo-elípticas, ovado-oblongas, ou suborbiculares, ápice 
acuminado, base obtusa, arredondada ou cordada, membranáceas a cartáceas, com 3,5-9,5cm de comprimento e 1-6,5cm de largura. Racemo terminal simples, flores rosas. Cálice com lobos lanceolados a ovado-lanceolados, longo-acuminados, esquamelas irregularmente denteadas. Corola tubular, com lobos curtamente acuminados. Estames com anteras auriculadas. Ovário ovóide-oblongo, apiculado, nectários 2 . Folículo com $10-37 \mathrm{~cm}$ de comprimento.

Fenologia: Flores de outubro a maio; frutos de dezembro a junho.

Nome popular: jalapa-silvestre.

Habitat: ocorre em campo, esparsamente, não formando agrupamentos.

Material examinado: Minas Gerais: Poços de Caldas, 30 nov. 1981, H.F. Leitão $F^{2} .1368$ A (UEC); 13 jan. 1981, L.S.K. Gouvêa et al., 745 (UEC); 3 nov. 1940, Mello Barreto 11002 (BHMH); aeroporto, 3 dez. 1940, Mello Barreto 11003 (BHMH); Caldas, 1 dez. 1873, Mosén 944 (S); 8-9 maio. 1870, Regnell I 281 (S); jan. 1862, Regnell I 284 (S); Campo do Saco, 2 dez. 1980, L.A.F. Mathes et al. 611 (UEC); Represa Saturnino de Brito, 14 out. 1964, O. Leocini e O. Roppa 319 (R).

8.6 - Mandevilla tenuifolia (Mikan) Woodson, Ann. Missouri. Bot. Gard. 20:679. 1933.

Erva com cerca de $15-25 \mathrm{~cm}$ de comprimento, com raízes napiformes, ramos finos, cilíndricos, puberulentos. Folhas opostas, oblongo-lineares a lineares, com $2,3-7,3 \mathrm{~cm}$ de comprimento e $0,75-2 \mathrm{~cm}$ de largura. Inflorencência lateral ou subterminal, em racemos simples. Flores vistosas e delicadas, de cor róseolilacíneas, congestas na extremidade do pedúnculo. Cálice com lobos lanceolados, ápice acuminado, glabros, escariosos, esquamelas em grupos alternos de 4 . Corola tubular salverforme, tubo mais largo próximo à fauce onde estão inseridos os estames, glabra. Estames com anteras ligeiramente auriculares. Ovário oblongo, glabro, nectários 2, compresso-ovóides. Fruto não visto.

Fenologia: Flores em dezembro.

Material examinado: Minas Gerais: Caldas, 1 dez. 1873, Mosén 941 (S).

8.7 - Mandevilla coccinea (Hook \& Arn.) Woodson, Ann. Missouri. Bot. Gard. 20:734. 1933.

Subarbusto ereto, com raízes tuberosas, caule delgado, cilíndrico. Folhas opostas, curtamente pecioladas ou subsésseis, oblongo-elípticas ou ovado-elípticas, de ápice agudo a curtamente apiculados, base arredondada a largamente obtusa, firmemente membranácea a subcoriácea, com 3-5,6 cm de comprimento e 1-3,5cm de largura. Inflorescência em racemos simples, terminais, laxas, com flores rosas ou avermelhadas, vistosas. Cálice com lobos lanceolados a ovado-lanceolados, 
acuminados, esquamelas alternas em grupos de 2. Corola hipocrateriforme, lobos da corola estendidos, ápices agudos. Estames com anteras auriculadas. Ovário oblongo, glabro, estigma longo, curtamente apiculado, nectários 2, oblongocompressos, de comprimento igual ou pouco menor ao do ovário. Folículos longos, glabros, com 19-23cm de comprimento.

Fenologia: flores de outubro a fevereiro; frutos de novembro a março.

Nome-popular: jalapa-sivestre-encarnada.

Habitat: ocorre em campo

Material examinado: Minas Gerais: Poços de Caldas, 30 nov. 1982, H. F. Leitão $F^{Q} .1755$ (UEC); 2 fev. 1982, H. F. Leitão $F^{2}$. et al. 1897 (UEC); 9 jan. 1919, Hoehne 2728 (SP); 10 jan. 1919, Hoehne 2791 (SP); fev. 1854, Lindberg 193 (S); 15 nov. 1873, Mosén 945 (S); 20 nov. 1875, Mosén 4262 (S); 20 nov. 1875, Mosén s/n (S); Alto de Santa Cruz, 15 out. 1965, O. Roppa 699 (R); Caldas, 14 dez. 1865, Regnell III 875 (S); Campo do Saco, 30 nov. 1981, H. F. Leitão F'. 1388 (UEC); 2. fev. 1980, L. A. F. Mathes et al. 601 (UEC), Cascata Véu das Noivas, 25 out. 1964, O. Roppa 407 (R); Km 69 da E.F. Mogiana, 10 nov. 1964, O Leoncini 438 (R); Seminário, 22 out. 1964, O. Roppa 382 (R); Serra de Caldas, 5 dez. 1862, Regnell III 875 (S).

8.8 - Mandevilla spigeliaefolia (Stadelm.) Woodson, Ann. Missouri. Bot. Gard. 20:736. 1933.

Subarbusto glabro, ereto, com raízes tuberosas. Folhas opostas, curtamente pecioladas a subsésseis, estreitamente oblongo-elípticas a lanceoladas, ápice agudo a acuminado, base obtusa a arredondada, firmemente membranáceas a cartáceas, apêndices nodais obsoletos, com $3-7,5 \mathrm{~cm}$ de comprimento e 1-1,5cm de largura. Inflorencência em racemos simples, terminais, com flores vistosas de cor rosa ou avermelhada. Cálice com lobos lanceolados a ovado-lanceolados, acuminados, escariosos, com esquamelas em grupos alternos de 2. Corola hipocrateriforme, lobos da corola estendidos, de ápices agudos. Estames com anteras auriculadas. Ovário ovóide-oblongo, glabro, estigma obscuramente apiculado, nectários 2 , ovóide-compressos com cercas de metade do comprimento do ovário. Fruto não visto.

Fenologia: flores de dezembro a fevereiro.

Habitat: ocorre em campo.

Material examinado: Minas Gerais: Caldas, 5 fev. 1876, Mosén 4264 (S); 22 jan. 1866, Regnell III 874 (S); 7 dez. 1854, Regnell IV 874 (S).

Neste levantamento das Apocynaceae de Poços de Caldas, Madevilla foi o gênero mais significativo, estando representado por 8 espécies e, destas, as mais coletadas foram: $M$. illustris, $M$. coccinea e $M$. velutina. Mandevilla venulosa não 
foi encontrada durante as coletas deste projeto, mas encontrada nas coleções de Mosén e Regnell, depositadas no Herbário de Estocolmo (S). Isto talvez se deva ao fato de que o local de coleta indicado nos rótulos das exsicatas (Caldas, MG), correspondia no século passado, a uma região muito grande, onde estava incluído o atual município de Poços de Caldas.

0 gênero Mandevilla foi também o mais encontrado nos ambientes campestres. Além deste, apenas Macrosiphonia e Forsteronia foram coletados nos diversos tipos de campos. Um maior número de gêneros foi encontrado nas matas: Aspidosperma, Condylocarpon, Forsteronia, Mandevilla, Peltastis, Prestonia e Rauwolfia. Condylocarpon isthimicum foi a espécie mais coletada neste tipo de ambiente.

\section{Agradecimentos}

Agradecemos à ALCOA S/A, na pessoa de Don Douane Willians, Gerente de Mineração, pelo apoio ao trabalho de campo; aos Curadores dos herbários BHMH, R, RB, S e SP, pelo empréstimo dos exemplares botânicos, à Esmeralda Z. Borghi, pela confeç̧ão das ilustrações, e à Benedita B. F. Martins, pela digitação do texto.

\section{Bibliografia}

AZAMBUJA, D. de 1947. Contribuição ao conhecimento das Apocynaceae encontradas no Brasil. Arquivos do Serviço Florestal. 3:9-112.

CANDIDO, J.F. \& J.J. GRIFFITH. 1978. Recomendações para a recuperação de superficies mineradas de bauxita. Viçosa. Escola Superior de Florestas. 170pp.

FALLEN, M. E. 1983. A taxonomic revision of Condylocarpon (Apocynaceae). Annals of the Missouri Botanical Garden. 70:149-169.

MARKGRAF, F. 1968. Apocynaceae in Reitz, P.R. (ed.) Flora Ilustrada Catarinense. Fasc. Apoc. I. Herbário Barbosa Rodrigues, Itajaí, p.1-112.

MOURÃO. M. 1951. Poços de Caldas: síntese histórico-social. São Paulo. Ed. Saraiva, 571pp.

MUELLER, J. 1860. Apocynaceae in von Martius, K.F.P. Flora Brasiliensis 6:I.1196, pls. 1-53.

WOODSON Jr., R.E. 1930. Studies in the Apocynaceae IV. A critical study of the Apocynoideae. Annals of the Missouri Botanical Garden 17(1-2):1-213.

WOODSON Jr., R.E. 1933. Studies in the Apocynaceae IV. The American Genera of Echitoideae. Annals of the Missouri Botanical Garden 20: 605-790.

WOODSON Jr., R. E. 1935. Studies en the Apocynaceae IV. The American Genera of Echitoideae. Annals of the Missouri Botanical Garden 22:153-306.

WOODSON Jr. R. E. 1936. Studies in the Apocynaceae IV. The American Genera of Echitoideae. Annals of the Missouri Botanical Garden 23:169-438. 